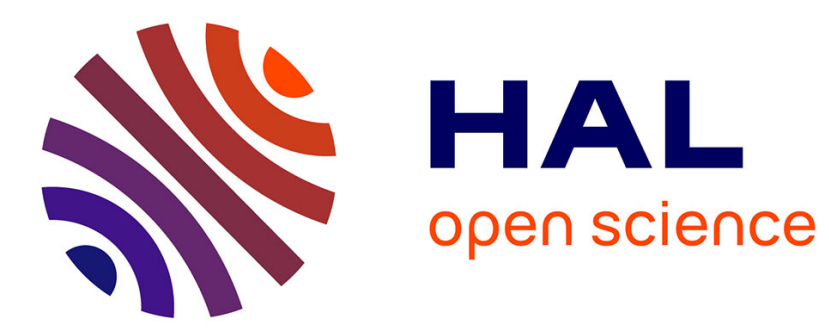

\title{
Internal Friction of Amorphous Zr65Al7.5Cu27.5-Films
}

\author{
L. Kempen, U. Harms, H. Neuhäuser, D. Scholz, E. Peiner, A. Schlachetzki
}

\section{To cite this version:}

L. Kempen, U. Harms, H. Neuhäuser, D. Scholz, E. Peiner, et al.. Internal Friction of Amorphous Zr65Al7.5Cu27.5-Films. Journal de Physique IV Proceedings, 1996, 06 (C8), pp.C8-643-C8-646. 10.1051/jp4:19968138 . jpa-00254570

\section{HAL Id: jpa-00254570 https://hal.science/jpa-00254570}

Submitted on 1 Jan 1996

HAL is a multi-disciplinary open access archive for the deposit and dissemination of scientific research documents, whether they are published or not. The documents may come from teaching and research institutions in France or abroad, or from public or private research centers.
L'archive ouverte pluridisciplinaire HAL, est destinée au dépôt et à la diffusion de documents scientifiques de niveau recherche, publiés ou non, émanant des établissements d'enseignement et de recherche français ou étrangers, des laboratoires publics ou privés. 


\title{
Internal Friction of Amorphous $\mathrm{Zr}_{65} \mathrm{Al}_{7.5} \mathrm{Cu}_{27.5}$-Films
}

\author{
L. Kempen, U. Harms, H. Neuhäuser, D. Scholz*, E. Peiner* and A. Schlachetzki* \\ Institut für Metallphysik und Nukleare Festkörperphysik, Germany \\ * Institut für Halbleitertechnik, Technische Universität, 38106 Braunschweig, Germany
}

\begin{abstract}
Using a vibrating reed device with micro structurized Si reeds the dynamic mechanical properties Young's modulus and damping of thin films deposited on the reeds are measured simultaneously with the curvature of the specimen. The curvature yields the internal stress of the film. As an example, measurements on amorphous $\mathrm{Zr}_{65} \mathrm{Al}_{7.5} \mathrm{Cu}_{27.5}$-films are shown and compared with measurements on amorphous splat cooled specimen of the same composition. A pronounced damping peak in the thin films is observed slightly below room temperature which is attributed to hydrogen relaxation jumps.
\end{abstract}

\section{Introduction}

In view of the growing importance of coating, the characterization of mechanical properties of thin films is essential in many applications. We have developed a dynamical measuring method using the vibration of a micro structurized Si reed to characterize mechanical properties of thin films deposited on this reed. In addition to the determination of Young's modulus and internal friction of the film the chosen technique with optical beam deflection permits an easy and simultaneous measurement of the curvature of the system. Thus internal stresses can be determined together with the dynamic mechanical quantities on the same specimen during temperature cycles $(140 \mathrm{~K}<\mathrm{T}<950 \mathrm{~K})$.

In the following, we present an application of this method to thin films of the amorphous alloy $\mathrm{Zr}_{65} \mathrm{Al}_{7.5} \mathrm{Cu}_{27.5}$. Alloys of this type have been discovered recently $[1,2]$ to exhibit an unusually wide range of the supercooled liquid between the glass transition temperature $\mathrm{T}_{g}$ and the crystallization temperature $\mathrm{T}_{c}$. We will show below the behaviour during structural relaxation of such thin films in comparison to "bulk"alloys of the same composition produced by splat cooling.

\section{Experimental}

Single crystalline Silicon provides an ideal support for thin films to be investigated by the vibrating reed method because of its very low intrinsic damping. Using well established techniques of micro structurization by anisotropic etching in $\mathrm{KOH}$, resonators of variable and precise geometry can be produced. The resonators are thin reeds of 4 to $14 \mathrm{~mm}$ length, 0.5 to $2 \mathrm{~mm}$ width and 5 to $100 \mu \mathrm{m}$ thickness. They are connected on one end with the thick substrate which facilitates their fixing to the specimen holder. The vibration is excited electrostatically and the freely decaying vibration of the reed is measured by means of a reflected optical beam of a laser diode, monitored by a position sensitive photo diode. This permits amplitudes from $200 \mu \mathrm{m}$ down to $10 \mathrm{~nm}$ to be detected. The vibrations are recorded, digitalized and fitted by an exponentially decaying sine function to yield frequency and damping coefficient with rather high precision.

For measuring the curvature (internal stress) of the specimen, the laser diode is displaced by a small known amount and the change in the position signal on the photo diode is recorded. This permits measurements of radii of curvature (r) with an accuracy $\Delta r^{-1}<0.02 r^{-1}+0.02 m^{-1}$.

Young's modulus of the film can be determined from the frequency of the vibrating reed prior and after film deposition, if thickness and density of substrate and film are known. Several corrections have to be considered resulting from lateral contraction and curvature, which is measured simultaneously. This will be discussed in detail elsewhere. 


\section{Results and Discussion}

\subsection{Structural relaxation and crystallization}

Measurements with constant heating rate to successively increasing maximum temperatures can be used to follow the process of structural relaxation and crystallization. The cooling and reheating parts of these cycles show the trivial effect of the temperature dependence of the elastic modulus; they may be used as a check of reproducibility and for separation of the pure relaxation effect.

\subsubsection{Splat cooled specimens}

From splats produced in a protecting atmosphere of pure Ar with a thickness of about $40 \mu \mathrm{m}$, stripes of $3 \mathrm{~mm}$ in width and $10 \mathrm{~mm}$ in length were cut and clamped on one end in the vibrating reed device. The ratio of the eigenfrequency of basic tone and overtones agree well with theoretical expectation indicating a negligible effect of clamping. At room temperature in the as-quenched state, Young's modulus of $E=75 \mathrm{GPa} \pm 10 \mathrm{GPa}$ was found. Heating cycles (Fig.1.) show, that a strong irreversible effect of structural relaxation sets in around $\mathrm{T}=350 \mathrm{~K}$ and saturates near the glass
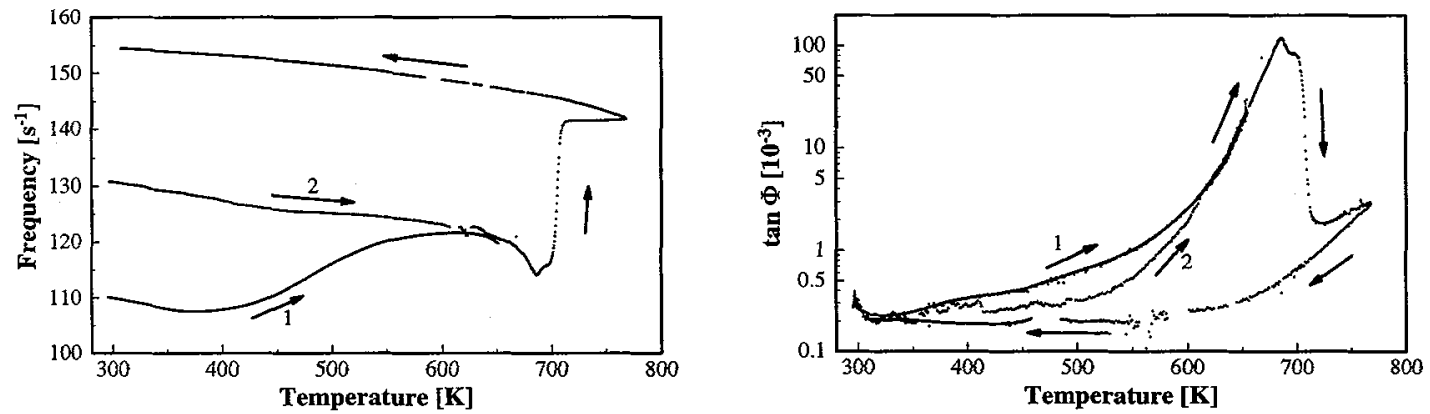

Fig. 1: Change of a) eigenfrequency and b) damping for a specimen cut from a splat cooled amorphous $\mathrm{Zr}_{65} \mathrm{Al}_{7.5} \mathrm{Cu}_{27.5}(\dot{\mathrm{T}}=3 \mathrm{~K} / \mathrm{min})$.

transition temperature $\mathrm{T}_{g}$ as indicated by the second heating run. The total change in frequency by $20 \%$ (or in Young's modulus by $45 \%$ ) with structural relaxation is rather large in comparison with other metallic glasses (cf. e.g. [3]). The second heating run crossing $\mathrm{T}_{g}$ indicates the glass transition by a strong depression of Young's modulus for $\mathrm{T}>\mathrm{T}_{g} \approx 640 \mathrm{~K}$, which in view of the heating rate of $3 \mathrm{~K} / \mathrm{min}$ reasonably fits to DSC and DMA results [2,4]. Around $\mathrm{T}=685 \mathrm{~K}$ crystallization sets in, connected with a pronounced irreversible increase of frequency corresponding to an increase of room temperature modulus to $140 \mathrm{GPa}$. This modulus change due to crystallization is again large in comparison with other metallic glasses [5]. The two stages of crystallization (the first leading to a quasicrystalline structure according to [6]) can be well recognized in (Fig.1a) and also in the measured damping (Fig.1b), where a rather large effect during crystallization occurs (note the log scale).

\subsubsection{Amorphous thin films}

Thin films of $\mathrm{Zr}_{65} \mathrm{Al}_{7.5} \mathrm{Cu}_{27.5}$ were produced by electron beam evaporation in UHV ( $\left.\mathrm{p}<10^{-9} \mathrm{mbar}\right)$ at room temperature with a deposition rate of $40 \mathrm{~nm} / \mathrm{min}$ up to a thickness of $200 \mathrm{~nm}$ onto structured Si substrates of $30 \mu \mathrm{m}$ thickness.

One set of successive heating cycles with increasing maximum temperature is shown in Fig. 2a. The Young modulus of the film in the as-quenched condition (which shows a compressive stress of -100 MPa) is about $\mathrm{E}=85 \pm 10 \mathrm{GPa}$ in reasonable agreement with the value of the splat specimen $(75 \pm 10 \mathrm{GPa})$. Its increase with structural relaxation sets in at the same temperature of $350 \mathrm{~K}$, too. Contrary to the splat, however, the structural relaxation and the connected increase of modulus continues steadily with each rising temperature cycle to much higher temperature values than for the splats; even for the highest heating run to $720 \mathrm{~K}$ a slight further increase in room-temperature modulus to $160 \mathrm{GPa}$ is observed. Also the internal stress at room temperature changes from compressive to tensile stress of $300 \mathrm{MPa}$ due to the structural relaxation. Therefore a correction of the lateral curvature effect was necessary to determine Young's modulus (maximum 20 GPa). 

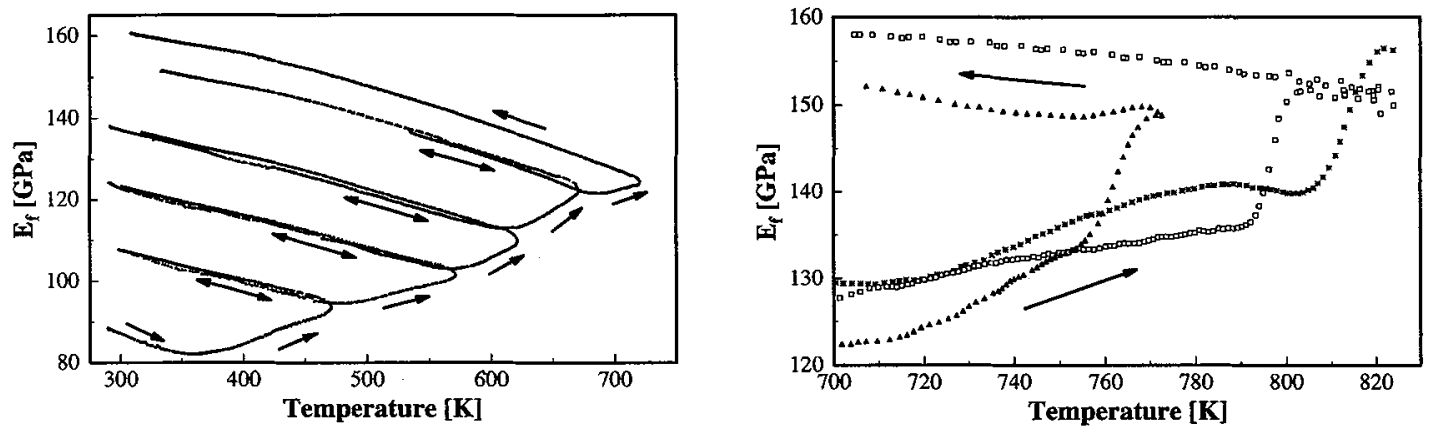

Fig. 2: a) Change of Young's modulus of $200 \mathrm{~nm} \mathrm{Zr}_{65} \mathrm{Al}_{7.5} \mathrm{Cu}_{27.5}$ thin film deposited on Si, during temperature cycles $(\dot{\mathrm{T}}=0.5 \mathrm{~K} / \mathrm{min}$ ) to successively increased temperature

b) Continuation of a) to higher temperatures for 3 different specimens

Surprisingly, a strong increase of the modulus with crystallization is not found in the temperature range around $\mathrm{T}_{c}$ of splat specimen $(690$ to $720 \mathrm{~K})$, but only at far higher temperature (in spite of the rather low heating rate), which differs considerably for various specimens (Fig. 2b), possibly due to variations in alloy composition or in oxidation condition. Fig. 3 shows the corresponding effects in damping; its absolute value, calculated from the measured damping of the compound resonator, is far below the damping in splat specimen.
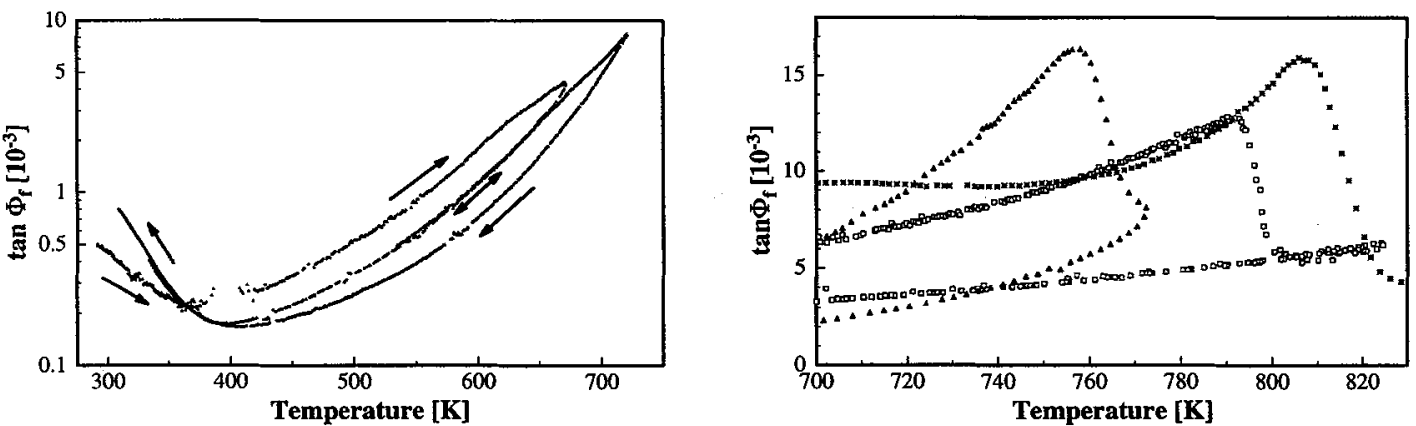

Fig. 3: a) Damping of the $\mathrm{Zr}_{65} \mathrm{Al}_{7.5} \mathrm{Cu}_{27.5}$ thin layer measured during the last two heating/cooling cycles of Fig. 2a. Note the increase at T<350 K (cf. Fig. 5)

b) Damping of the 3 specimens in the elevated temperature region as shown in Fig. 2

\subsection{Damping peak in the range of lower temperatures}

The measurements in Fig. 3a indicate an increase of the damping coefficient at lower temperatures $<360 \mathrm{~K}$. It belongs to a pronounced damping peak of the amorphous layer of $\mathrm{Zr}_{65} \mathrm{Al}_{7.5} \mathrm{Cu}_{27.5}(\mathrm{~s}$. Fig. 4), which shows all characteristics typical for relaxation of hydrogen in amorphous $\mathrm{Zr}$ based alloys (cf. e.g. $[7,8]$ ).

From the shift of the temperature of the peak maximum with change in vibration frequency, an activation energy of $0.45 \mathrm{eV} \pm 0.05 \mathrm{eV}$ and a preexponential time $\tau_{0}=10^{-12 \pm 1} \mathrm{~s}$ is derived, which are also consistent with hydrogen jumps.

This interpretation is further corroborated by comparison with the splat specimen. In the asreceived condition the splat specimen shows a rather small peak at somewhat higher temperature $\left(\mathrm{T}_{p} \approx 265 \mathrm{~K}\right)$ than the film $\left(\mathrm{T}_{p} \approx 245 \mathrm{~K}\right)$. After loading the specimen with hydrogen in a pressure vessel $(24 \mathrm{~h}$ at 200 bar at $420 \mathrm{~K}$ ) the splat specimen shows a stronger peak around $230 \mathrm{~K}$ with a height exceeding that of the film. It means that hydrogen enters the splat specimen only with some difficulty, contrary to the thin alloy layer (where only about 10 monolayers of hydrogen would be sufficient), produced under UHV-conditions. The observed peak shift to higher temperature with increasing concentration also corresponds to expectation (cf. [7-9]).

By means of temperature cycling up to various temperatures maximum, the influence of structural relaxation on the hydrogen peak of the $\mathrm{Zr}_{65} \mathrm{Al}_{7.5} \mathrm{Cu}_{27.5}$ films was examined. Fig. 5 shows that, up to 
a maximum annealing temperature of $570 \mathrm{~K}$ (with heating rate of $0.5 \mathrm{~K} / \mathrm{min}$ ), the hydrogen peak continuously decreases with an only slight shift to higher temperatures. This indicates a decrease in hydrogen concentration. However, after annealing at $\mathrm{T}_{a}=620 \mathrm{~K}$, another peak appears and increases on further annealing $\left(\mathrm{T}_{a}=670 \mathrm{~K}\right)$ with a peak maximum at a distinctly $(50 \mathrm{~K})$ higher temperature. It is not yet clear whether this peak is also produced by hydrogen, or whether it is due to another mechanism. The first interpretation is suggested by the same typical peak asymmetry (Fig. 5) while the increase of the peak could only mean a drastic increase of the relaxation strength. Thus the hydrogen relaxation jumps might be used as an atomic probe of the atomistic environments in the structure as suggested by Sinning [8].

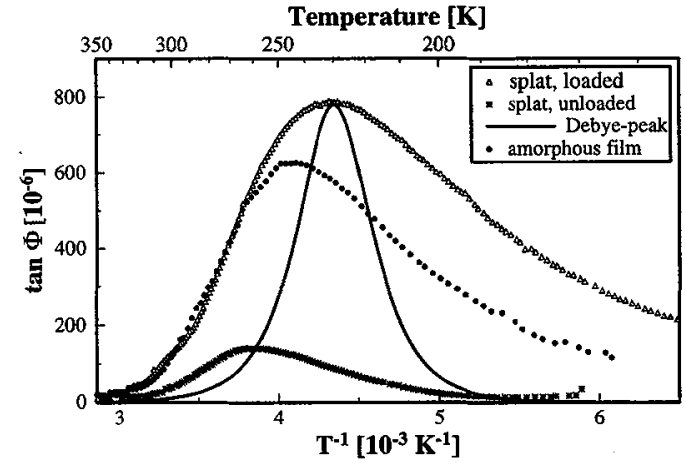

Fig. 4: Comparison of damping peaks of amorphous $\mathrm{Zr}_{65} \mathrm{Al}_{7.5} \mathrm{Cu}_{27.5}$ layer and -splats (as received and loaded with hydrogen)

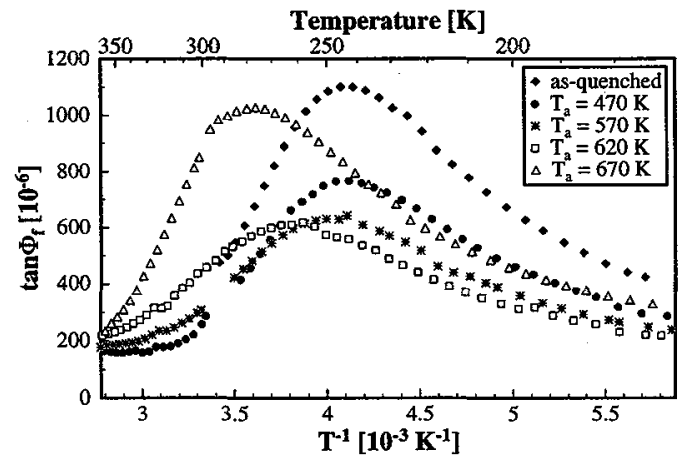

Fig. 5: Effect of structural relaxation on the damping peak for an amorphous layer $\left(T_{a}=\right.$ maximum temperature of the preceding heating cycle)

During annealing in the amorphous state the hydrogen loaded splat specimen shows an only slight decrease and shift of the maximum to higher temperatures. Annealing into the glass transition with full relaxation of all internal stresses resulted in no further change of the peak. These observations, together with a lacking dependence on the vibrating amplitude (checked for $10^{-7}<\epsilon<5 \cdot 10^{-5}$ for splat specimens and up to $\epsilon \approx 5 \cdot 10^{-4}$ for thin films) do not support an interpretation of the peak in terms of internal stress distributions originated from local plastic deformations by hydrogen as suggested by Khonik and Spivak [10]. Rather we believe that the damping peak is produced by relaxation jumps of hydrogen atoms in the $\mathrm{Zr}_{65} \mathrm{Al}_{7.5} \mathrm{Cu}_{27.5}$ structure, which appears to change its character also in the thin film around $\mathrm{T}=620 \mathrm{~K}$.

\section{Acknowledgements}

The authors are indebted to Prof.K. Samwer, and Dr. M. Moske and Dipl.-Phys. B. Reinker, Institute of Applied Physics of the University of Augsburg, for preparation of the thin films and of the splat specimens as well as to Priv. Doz. Dr. H.R. Sinning for loading the splat specimens with hydrogen. We are also grateful to them for fruitful discussions. This work was performed in the Graduiertenkolleg "Metrologie in Physik und Technik"of the Technical University of Braunschweig and the Physikalisch-Technische Bundesanstalt.

\section{References}

[1] A. Inoue, T. Zhang and T. Masumoto. J. NonCryst. Sol. 150,396-400 (1992)

2. A. Peker and W.L. Johnson Appl. Phys. Lett., 63, 2342-2344 (1993).

3] B. Porscha and H. Neuhäuser Scripta Metall. et Mater., 32, 931-936 (1995).

4) R. Rambousky, M Moske and K. Samwer. Z. PhysikB, 99,387-391 (1996).

[5] H.U. Künzi. Mechanical properties of metallic glasses, in Glassy Metalls II

Ed. H. Beck and H.J. Güntherodt, Springer Verlag, Berlin (1983).

[6] U. Köster, J. Meinhardt, S. Roos and H. Liebertz, Appl.Phys.Lett. (in press)

7 B.S. Berry and W.C. Pritchet. Z. Phys. Chem., NeueFolge, 163, 381.390 (1989)

8] H.-R. Sinning Defect and Dif fusion Forum, 123-124, 1-30(1995).

9] U. Stolz, M. Weller and R. Kirchheim ScriptaMet., 20, 1361-1366(1986).

[10] V.A. Khonik and L.V. Spivak. ActaMater., 44, 367-381 (1996). 